Journal of Applied Pharmaceutical Science Vol. 5 (10), pp. 073-079, October, 2015

Available online at http://www.japsonline.com

DOI: $10.7324 / \mathrm{JAPS} .2015 .501013$

ISSN 2231-3354 (cc) BY-NC-sA

\title{
Degradation of cefdinir from pharmaceutical waste water using immobilized Candida sp. SMN04 and biofilm formed on gravels
}

\author{
Adikesavan Selvi, Monidipa Banerjee, Nilanjana Das* \\ School of Bio Sciences and Technology,VIT University,Vellore- 632014,Tamilnadu, India.
}

\begin{tabular}{|c|c|}
\hline ARTICLE INFO & ABSTRACT \\
\hline Article history: & Cefdinir being a semi-synthetic third generation cephalosporin antibiotic is considered as an emerging pollutant \\
\hline Received on: $21 / 08 / 2015$ & which demands removal from environment. Degradation of cefdinir by yeast Candida sp. SMN04 immobilized \\
\hline Revised on: 03/09/2015 & on various single and hybrid matrices was investigated using entrapment method. The biofilm forming ability of \\
\hline Accepted on: 26/09/2015 & Candida sp. was evaluated by crystal violet staining assay and the formed biofilm was monitored by SEM and \\
\hline Available online: $28 / 10 / 2015$ & AFM analysis. The amount of exopolysaccharides (EPS) produced by Candida sp. was quantified and \\
\hline $\begin{array}{l}\text { Key words: } \\
\text { Biofilm, } \\
\text { Cefdinir,Degradation, } \\
\text { Immobilization, } \\
\text { Pharmaceutical wastewater. }\end{array}$ & $\begin{array}{l}\text { characterized by FTIR, HPLC and TGA analysis respectively. Cefdinir degradation from pharmaceutical } \\
\text { wastewater was found to be } 96.6 \% \text { and } 92.2 \% \text { by PVA-alginate immobilized yeas tand yeast biofilm formed on } \\
\text { gravels over a period of } 48 \mathrm{~h} \text { in batch mode. Effectiveness of the process was also tested involving continuous - } \\
\text { flow column studies. This is the first successful attempt on cefdinir degradation using immobilized yeast cells } \\
\text { and yeast biofilm on solid substrate. }\end{array}$ \\
\hline
\end{tabular}

\section{INTRODUCTION}

Among all the pharmaceutical compounds, antibiotics and drugs are considered to be the most significant because of its high usage and consumption in both veterinary and human medicine (Benitez et al., 2011). Several types of pharmaceutical residues were reported to exist in various aqueous matrices, which have received a lot of attention due to their ubiquity and adverse health effects (Arriaga et al., 2009; Behera et al., 2011). Among those residuals, cefdinir, a semi-synthetic third generation cephalosporin antibiotic is of great concern because of its extensive usage for the treatment of acute respiratory related disorders and mild skin infections in adults and children. Removal of cephalosporin antibiotics becomes an inevitable issue to preserve the environment as it contribute to increase the toxic strength of the effluent and production of third-generation cephalosporin resistant microorganisms (Duan, 2009; Endimiani et al., 2012). Several physical and chemical techniques have been proposed in the last decades to remove antibiotic compounds from wastewater, which are of limited applicability due to inefficiency of remediating high strength wastewater, high

* Corresponding Author

Email: mail id:nilanjana00@lycos.com operating cost, huge labor requirement, high equipment cost, intervention of toxic by-products etc. (Homem and Santos,2011). Hence, biological treatment is universally preferred because it is economical, environmental friendly and can offer the possibility of complete mineralization (Liu et al., 2009). There are reports on microorganisms viz. Pseudomonas putida and Pseudomonas fluorescens (Krishnan et al., 2012), Bacillus and Bacteriods (Wagner et al., 2011) and Ustilago sp. SMN03 (Selvi and Das, 2014a) which are capable of using cephalosporin derivatives as the sole source of carbon and energy. But free microbial cells have certain limitations viz., small particle size, possible clogging and low mechanical strength of the biomass (Godjevargova et al., 2004). Microbial cells entrapped in suitable matrix have been shown to have improved tolerance to a variety of toxic and recalcitrant compounds (Chen et al., 2008; Sarma and Pakshirajan, 2011). Immobilization of microbial cells has received increasing interest in the field of wastewater treatment (Tong et al., 2013; Wang et al., 2012). The advantages of immobilized cells include increased degradation rate, toxicity tolerance, reusability, good operational stability and low processing costs (Kadakol et al., 2011; Magrí et al., 2012; Wang et al., 2012).

Biofilm is a highly rigid structure developed by aggregation of the microbial cells, enclosed within a matrix of exopolysaccharides (EPS) onto any inert solid material. 
They are resistant to a variety of environmental problems. EPS are microbial exudates consisting of a range of structural homopolymers and branched heteropolymers that carry out many functions such as structural integrity, cell-surface adherence and protection against environmental stress (Stoodley et al., 2002). Biofilm-based processes are useful for wastewater treatment because of their simplicity, reliability, easy usage and stability (Whiteley and Lee, 2015). Candida sp. SMN04 isolated from pharmaceutical wastewater has already been reported which is capable of using cefdinir as sole carbon and energy source (Selvi and Das, 2014b). So far, no report is available on cefdinir degradation from pharmaceutical wastewater using immobilized yeast and yeast biofilm. Hence, the objectives of the present study are (i) to investigate the cefdinir degradation efficiency of Candida sp. SMN04 immobilized in single and hybrid matrices, (ii) to study the biofilm forming capacity of Candida sp. SMN04, (iii) to quantify and characterize the exopolysaccharides (EPS) produced by Candida sp. SMN04 and (iv) to investigate the cefdinir degradation from pharmaceutical waste water using immobilized PVA-alginate beads and biofilm formed on gravels in batch and column mode.

\section{MATERIALS AND METHODS}

\section{Yeast and growth conditions}

The yeast species, Candida sp. SMN04 (KF963314.1) isolated from pharmaceutical wastewater was used in this work (Selvi and Das, 2014b). The cefdinir degrading yeast was maintained on yeast extract peptone dextrose (YEPD) slants supplemented with $100 \mathrm{mg} \mathrm{L}^{-1}$ of cefdinir.

\section{Pharmaceutical wastewater}

Pharmaceutical wastewater was collected from cephalosporin production unit, Chennai, India. The physicochemical parameters such as $\mathrm{pH}$, Chemical Oxygen Demand (COD), Biological Oxygen Demand (BOD), Total Dissolved Solids (TDS) and Total Suspended Solids (TSS) were estimated following the standard methodologies of APHA (2005). The cefdinir concentration in the waste water was measured using UVvisible spectrophotometer.

\section{Immobilization of yeast}

The preparation of beads using immobilization matrices viz. sodium alginate, CMC, chitosan and agar was carried out under sterilized condition. Sodium alginate and yeast suspension mixture was gently dropped into $\mathrm{CaCl}_{2}$ solution $(0.2 \mathrm{M})$ to form alginate beads. The mechanical stability of the beads are enhanced by curing the immobilized beads in $0.2 \mathrm{M} \mathrm{CaCl}_{2}$ solution for $2 \mathrm{~h}$. Immobilized beads of yeast suspension and $\mathrm{CMC}$ solution mixture was prepared by gently dropping the mixture into $0.05 \mathrm{M} \mathrm{FeCl}$ solution and beads were further cured in the same solution for $1 \mathrm{~h}$. Chitosan solution was prepared in $100 \mathrm{ml}$ of $1 \%$ acetic acid and thoroughly mixed with yeast suspension. Then the mixture was gently dropped into $8 \% \mathrm{NaOH}$ solution for the formation of chitosan immobilized beads. The immobilized beads were separated from the solution after $30 \mathrm{~min}$ and washed twice with $200 \mathrm{~mL}$ sterile distilled water for $15 \mathrm{~min}$. Agar solution (2\%) was prepared under sterilized condition and melted by heating. Yeasts suspension was mixed with $100 \mathrm{~mL}$ of the agar solution (cooled to temperature $\leq 40{ }^{\circ} \mathrm{C}$ ) under sterilized condition to achieve a cell concentration above $4 \mathrm{~g}$ wet weight $\mathrm{L}^{-1}$. Mixture of agar and yeast suspension was gently poured into sterile petri plates coated with a thin layer of refined sunflower oil and allowed to solidify for $30 \mathrm{~min}$ at $4{ }^{\circ} \mathrm{C}$. The solidified immobilized agar block was cut into equal size cubes $(\sim 2 \mathrm{~mm})$. For the preparation of hybrid matrix, PVA $\left(10 \mathrm{~g} \mathrm{~L}^{-1}\right)$ and sodium alginate $\left(10 \mathrm{~g} \mathrm{~L}^{-1}\right)$ were mixed in distilled water at $80{ }^{\circ} \mathrm{C}$. The solution was cooled and mixed thoroughly to obtain a homogenous suspension. Aliquot of $5 \mathrm{~mL}$ yeast suspension was added to it. The final matrix ratio was maintained as 1:1. The PVA-alginate mixtures were extruded in $0.2 \mathrm{M} \mathrm{CaCl}_{2}$ to form beads of diameter $0.26 \pm 0.2 \mathrm{~cm}$. The resulting beads were washed with saline and used for experiments. Similar methodology was followed for preparation of glycerol-alginate beads and the same ratio $(1: 1)$ as mentioned above was maintained for the experiments.

\section{Screening of different matrices for cefdinir degradation}

To screen the best matrix for immobilization and cefdinir degradation, Candida sp. SMN04 immobilized on various matrices were transferred into $50 \mathrm{~mL}$ of YEPD medium containing cefdinir $\left(300 \mathrm{mg} \mathrm{L}^{-1}\right.$ ) and incubated at $28^{\circ} \mathrm{C}$ on a rotary shaker at $120 \mathrm{rpm}$. The samples were collected at regular time intervals to monitor degradation. The above procedure was also followed for studying the biodegradation of cefdinir by free cells by inoculating free cells of Candida sp. to the YEPD medium containing cefdinir (300 $\mathrm{mg} \mathrm{L}^{-1}$ ) and incubated under same conditions stated above.

\section{Analytical methods for cefdinir degradation}

Culture broth containing immobilized yeast was centrifuged at $8400 \mathrm{xg}$ for $10 \mathrm{~min}$ and the supernatant was collected at regular time intervals for estimation of residual cefdinir concentration. Cefdinir concentration was analyzed by UV-Visible spectrophotometer (Hitachi U-2800) following the method Cabri et al. (2006). The absorbance was measured at 285 $\mathrm{nm}$. The percentage of cefdinir degradation was calculated as follows,

$$
\text { Cefdinir degradation efficiency }(\%)==\frac{C_{i}-C_{f}}{C_{i}} \times 100
$$

where, $C_{i}$ is the initial cefdinir concentration and $C_{f}$ is the final cefdinir concentration.

Pellets were dried in a hot air oven at $60{ }^{\circ} \mathrm{C}$ and the dry weight of immobilized cells was measured. The dry weight of the beads without yeast cells was used as abiotic control.

\section{Biofilm formation and quantification}

Crystal violet (CV) staining assay was done to assess the cell attachment and formation of biofilms in a 96-well microtiter plate following the method of O'Toole and Kolter (1998) with 
minor modifications. Microtiter plates were inoculated by adding $150 \mu \mathrm{L}$ of inoculum grown at 24 and $48 \mathrm{~h}$ and incubated at $28^{\circ} \mathrm{C}$. After incubation, the liquid supernatants were carefully removed using a micropipette and wells were rinsed with $180 \mu \mathrm{L}$ of phosphate buffered saline (PBS). The attached yeast biomass was stained with $180 \mu \mathrm{L}$ of filtered $0.1 \% \mathrm{CV}$ solution for $10 \mathrm{~min}$. The wells were then rinsed thrice with $200 \mu \mathrm{L}$ of PBS and were airdried. The remaining CV stain was solubilized by adding $180 \mu \mathrm{L}$ of absolute ethanol and the light absorbance was measured at 570 nm with a Model 680 Microplate Reader (Bio-Rad laboratories Ltd, UK). Biofilm formation was scored based on absorbance value of an inoculum-free medium (control) and the biofilm. The ratio of $\mathrm{A}_{\text {biofilm }} / \mathrm{A}_{\text {control }}$ gives the biofilm score.

The biofilm formation was monitored using atomic force microscopy (AFM) (Nanosurf, Switzerland; Model: easyScan2) following the procedure of Lal et al. (2010) and scanning electron microscopy (SEM) (EVO series-MA15 SEM) analysis following the procedure of Hawser and Douglas (1994) with minor modifications.

\section{Quantification and characterization of exopolysaccharides (EPS)}

Basal minimal media containing $4 \%$ glucose, $0.3 \mathrm{NaNO}_{3}$, $0.03 \mathrm{MgSO}_{4} .7 \mathrm{H}_{2} \mathrm{O}, 0.03 \mathrm{KH}_{2} \mathrm{PO}_{4}, 0.1 \%$ yeast extract ( $\mathrm{pH} 6.0$ ) was used for EPS production (Sajna et al. 2013). The culture conditions were maintained for 6 days at $30{ }^{\circ} \mathrm{C}$ with $120 \mathrm{rpm}$ agitation. Cell growth and EPS yield of the culture broth were studied at regular time intervals. Cell growth was determined by taking an aliquot of the medium, centrifuging it at $8400 \mathrm{xg}$ for $10 \mathrm{~min}$ at $4{ }^{\circ} \mathrm{C}$ and drying the pellet at $60{ }^{\circ} \mathrm{C}$ for $48 \mathrm{~h}$ and weighed. To determine the EPS yield, the cell-free culture broth was precipitated by mixing the supernatant with twice the volume of chilled ethanol and incubated at $4{ }^{\circ} \mathrm{C}$ for $4 \mathrm{~h}$. The obtained EPS was centrifuged at $8400 \mathrm{xg}$ for $10 \mathrm{~min}$ at $4^{\circ} \mathrm{C}$. The precipitated EPS was washed twice with deionized water to remove the impurities and dried at $60{ }^{\circ} \mathrm{C}$ for $48 \mathrm{~h}$.

Purified EPS was characterized using an IR-affinity-1FT-IR spectrophotometer (Shimadzu) using $\mathrm{KBr}$ disc, scanned in the range of 4000 to $500 \mathrm{~cm}^{-1}$. The monomeric carbohydrate composition in the EPS was determined after hydrolysis with $2 \mathrm{M}$ $\mathrm{H}_{2} \mathrm{SO}_{4}$ at $105{ }^{\circ} \mathrm{C}$ for $3 \mathrm{~h}$. The hydrolysate was then neutralized with calcium carbonate and filtered through $0.22 \mu \mathrm{m}$ syringe filter. The monomers were determined by HPLC (Shimadzu) using carbohydrate analysis column. Deionized water was used as mobile phase and a flow rate of $0.6 \mathrm{~mL} \mathrm{~min}^{-1}$ was maintained.

The thermal behavior and the corresponding weight loss of the EPS produced by Candida sp. SMN04 was determined by the TGA analysis using thermal analyzer (DTG-60, Shimadzu, Japan). The sample was subjected to a temperature range of 0 to $700^{\circ} \mathrm{C}$ under nitrogen atmosphere at a heating rate of $10^{\circ} \mathrm{C} \mathrm{min}^{-1}$.

\section{Formation of biofilm on gravels}

Biofilm was grown on gravels in YEPD medium for a period of 10 days. After incubation, the biofilm formed on gravels were washed with phosphate buffer to get rid of loosely attached cells. The washed gravels with the biofilm was then immersed in minimal media containing cefdinir $300 \mathrm{mg} \mathrm{L}^{-1}$ for 6 days to monitor cefdinir degradation.

\section{Degradation of cefdinir present in pharmaceutical wastewater}

Experiments on degradation of cefdinir present in pharmaceutical wastewater were conducted in batch mode using PVA-alginate immobilized yeast and yeast biofilm formed on gravels by Candida sp. SMN04. The gravels coated with yeast biofim and PVA-alginate immobilized yeast cells, each of $5 \mathrm{~g}$ were immersed in $100 \mathrm{~mL}$ of pharmaceutical wastewater in two separate $250 \mathrm{~mL}$ Erlenmeyer flasks. All the experiments were performed in triplicates under optimal conditions of $\mathrm{pH} 6.0$ and $30^{\circ} \mathrm{C}$. The cefdinir degradation was monitored at regular time intervals and data presented are the mean of triplicates.

In order to demonstrate the practical application of operating conditions during the degradation process in the present study, column experiments were conducted using cefdinir containing pharmaceutical wastewater. The wastewater was fed through a glass column packed with PVA-alginate immobilized yeasts at a bed height of $12 \mathrm{~cm}$ and flow rate of $1.0 \mathrm{ml} \mathrm{min}$ controlled by peristaltic pump (Rivotek ${ }^{\mathrm{TM}}$ ).

The samples collected at regular intervals from the exit were analysed for cefdinir degradation. Similar procedure was followed for the treatment of pharmaceutical wastewater in column packed with gravels coated with biofilm formed by Candida sp. SMN04.

\section{RESULTS AND DISCUSSION}

\section{Development of immobilized cells and viability}

The yeast species, Candida sp. SMN04 was immobilized in various single and hybrid matrices viz., sodium alginate, $\mathrm{CMC}$, chitosan, agar, PVA-alginate and glycerol-alginate. The cell viability was checked over a period of 12 weeks as the stability of the beads was found to play a major role in conversion of substrate to products (Idris and Suzana, 2006). From Fig. 1, it can be seen that, the yeast cells immobilized with PVA-alginate showed more stability and retained maximum cell viability than the other tested matrices.

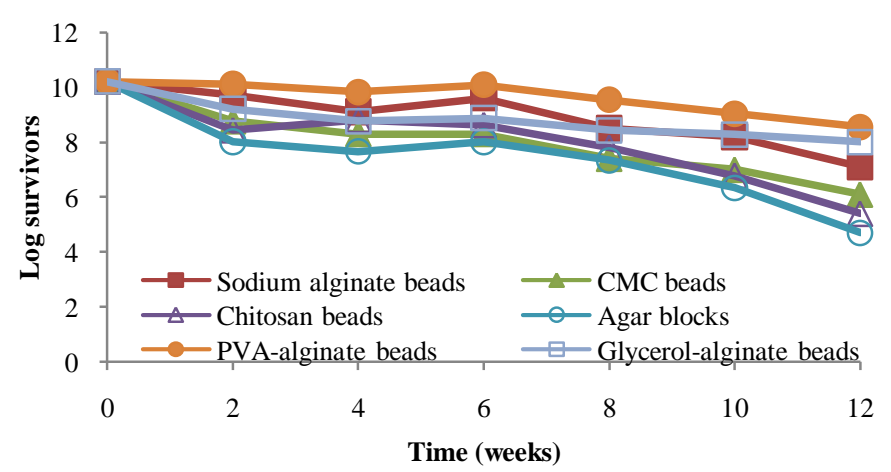

Fig. 1: Time course of changes in the viability of Candida sp. SMN04 immobilized in various single and hybrid matrices. 
Among synthetic carriers, PVA is most preferred because it is non-toxic, non- carcinogenic (Zhang et al., 2007). It also has relatively good tensile stress, impact strength, high water affinity, wear resistance, good biocompatibility, processability, minimal cell and protein adhesion and excellent electrical insulation properties (Yujian et al., 2006; Zhang et al., 2007). In case of PVA-alginate hybrid matrix, PVA contributes strength and high crosslinking capacity whereas alginate reduces the agglomeration and increases the surface properties (Sasaki et al., 2007).PVAalginate as a promising carrier to immobilize microbes has been reported by various workers (Yujian et al., 2006; Zhang et al., 2007; El-Naas et al., 2013).

Table 1: Cefdinir degradation potential of free cells, immobilized yeast cells and biofilm grown on gravels grown in $\mathrm{MB}$ containing cefdinir at an initial concentration of $300 \mathrm{mg} \mathrm{L}^{-1}$.

\begin{tabular}{lc}
\hline Inoculum/Immobilized matrix & Cefdinir degradation $(\boldsymbol{\%})$ \\
\hline Abiotic control & 0.01 \\
Free yeast cells & $84.0 \pm 0.4$ \\
Sodium alginate beads & $85.6 \pm 1.8$ \\
CMC beads & $84.4 \pm 0.6$ \\
Chitosan beads & $81.7 \pm 1.1$ \\
Agar & $79.2 \pm 1.3$ \\
PVA-alginate & $88.5 \pm 1.6$ \\
Glycerol alginate & $85.8 \pm 1.2$ \\
Biofilm grown on gravels & $85.4 \pm 1.0$ \\
\hline
\end{tabular}

Values are mean of replicate \pm SD

Cefdinir degradation by immobilized Candida sp. SMN04 in various matrices were performed in batch cultures and are presented in Table 1.The obtained results showed that the yeast species immobilized in PVA-alginate showed maximum cefdinir degradation over a period of 6 days compared to free cells. In a previous study, Selvi and Das (2014b) reported $84 \%$ of cefdinir degradation using free cells of yeast, Candida sp. SMN04 with an initial concentration of $250 \mathrm{mg} \mathrm{L}^{-1}$ at the end of 6 days. Whereas, in the present study, PVA-alginate immobilized yeast degraded $88.5 \pm 1.6 \%$ with an initial concentration of $300 \mathrm{mg} \mathrm{L}^{-1}$ of cefdinir within the same period of time confirming the potentiality of PVAalginate immobilized yeast cells to degrade cefdinir more effectively than the free cells.

\section{Biofilm formation and quantification}

The adherence and subsequent biofilm formed by the yeast isolate, Candida sp. SMN04 was studied using crystal violet (CV) staining assay. The biofilm score of the yeast was calculated as 9.2. From the obtained results, it was evident that Candida sp. SMN04 was capable of single-species biofilm formation. The sequence of biofilm formation at 24 and $48 \mathrm{~h}$ were monitored by AFM images (Fig. 2a,b) and SEM images (Fig. 2c,d) respectively.

\section{Exopolysaccharides (EPS) production and characterization}

The EPS production protects the microbial cells from environmental chemical toxicity (Chandran and Das, 2011). The total exopolysaccharides (EPS) producing capacity of Candida sp. SMN04 was found to be $0.29 \mathrm{mg} \mathrm{mL}^{-1}$ (expressed per $10^{8} \mathrm{CFU}$ ). The results showed that, Candida sp. SMN04 could establish a thick and mucilageneous yeast biofilm on gravels after two weeks of incubation in cefdinir containing medium. For characterization, FTIR spectrum of the EPS produced by Candida sp. SMN04 was analysed and shown in Fig. 3(a). The adsorption bands obtained revealed typical polymeric structure of carbohydrates. Sharp peaks at $3259.70 \mathrm{~cm}^{-1}$ and $3201.83 \mathrm{~cm}^{-1}$ indicated the stretching vibration of $\mathrm{O}-\mathrm{H}$ groups of carbohydrate. This characteristic group was responsible for the water solubility of EPS (Karbowiak et al., 2011). Two adsorption bands at2922.16 and $2852.12 \mathrm{~cm}^{-1}$ represented the C-H stretching of the methyl and methylene groups. The stretching vibration of amide group was found in the region of $1656.78 \mathrm{~cm}^{-1}$ (Fanet al., 2011). Similarly, peak at $1427.32 \mathrm{~cm}^{-1}$ could be assigned to C-O band of carboxylic group (-COO) (Wang et al., 2010). Presence of band at $1074.35 \mathrm{~cm}^{-1}$ suggested the monoscaaharide constituents of pectic and hemicellulosic polysaccharides. The adsorption band at 977.91 $\mathrm{cm}^{-1}$ suggested the presence of sugar monomers such as glucose, galactose and mannose in the EPS produced by Candida $s p$. On the contrary, absence of band at $870-890 \mathrm{~cm}^{-1}$ indicated that $\beta$ glycosoidic linkage was not present in the EPS (Tao et al., 2008). Therefore, FTIR analysis of the EPS produced by yeast strain showed characteristic bands for EPS. TGA measurement is used to study the thermal stability of the materials which measures the change of sample mass (weight loss associated with dehydration, decomposition and oxidation of sample) as a function of temperature (Ahmed et al., 2013). TGA of the EPS extracted from Candida sp. SMN04 is shown in Fig. 3(b). The plot of TGA curve is the conversion of TGA signal to percent weight loss against the sample temperature ${ }^{\circ} \mathrm{C}$. Thermogram of EPS revealed that the loss of weight occurred initially ( $4 \%)$ in the temperature between $22^{\circ} \mathrm{C}$ to $100^{\circ} \mathrm{C}$ which may be associated with the loss of moisture content. The moisture content of the EPS is due to the presence of high level of carboxyl group which is bound to water molecule (Kumar et al., 2004) and alcohol content (Ismail and Nampoothiri, 2010). This slow decomposition of the EPS can be attributed to the presence of some thermostable saccharide moiety (Sajna et al., 2013). The onset of decomposition occurred with weight loss of approximately $\sim 12 \%$ at $234{ }^{\circ} \mathrm{C}$, which indicates that the EPS sample was $88 \%$ stable until $234{ }^{\circ} \mathrm{C}$. However, the compound was found to decompose to a total weight loss of $\sim 65 \%$ when heated at higher temperatures upto $700{ }^{\circ} \mathrm{C}$. The results confirmed the thermostabilty nature of the produced EPS at higher temperatures. Similar results were reported by other workers (Taveres et al., 2005; Poli et al., 2010). Thermostability of EPS is an important characteristic considered for food industry as the manufacturing and processing of several food preparations are carried out at higher temperatures. Hence, EPS produced by Candida sp. SMN04 being thermostable can serve as an ideal Candidate for food industry. Sugar analysis by HPLC of Candida sp. EPS revealed the presence of peak corresponding to heteropolysaccharides of glucose, galactose and mannose as shown in Fig. 3(c). The quality and quantity of the EPS depends on the carbon source and culture conditions (Laws et al, 2001). The obtained result was in consensus with the contents of EPS produced by Pseudozyma sp. (Sajna et al., 2013). 

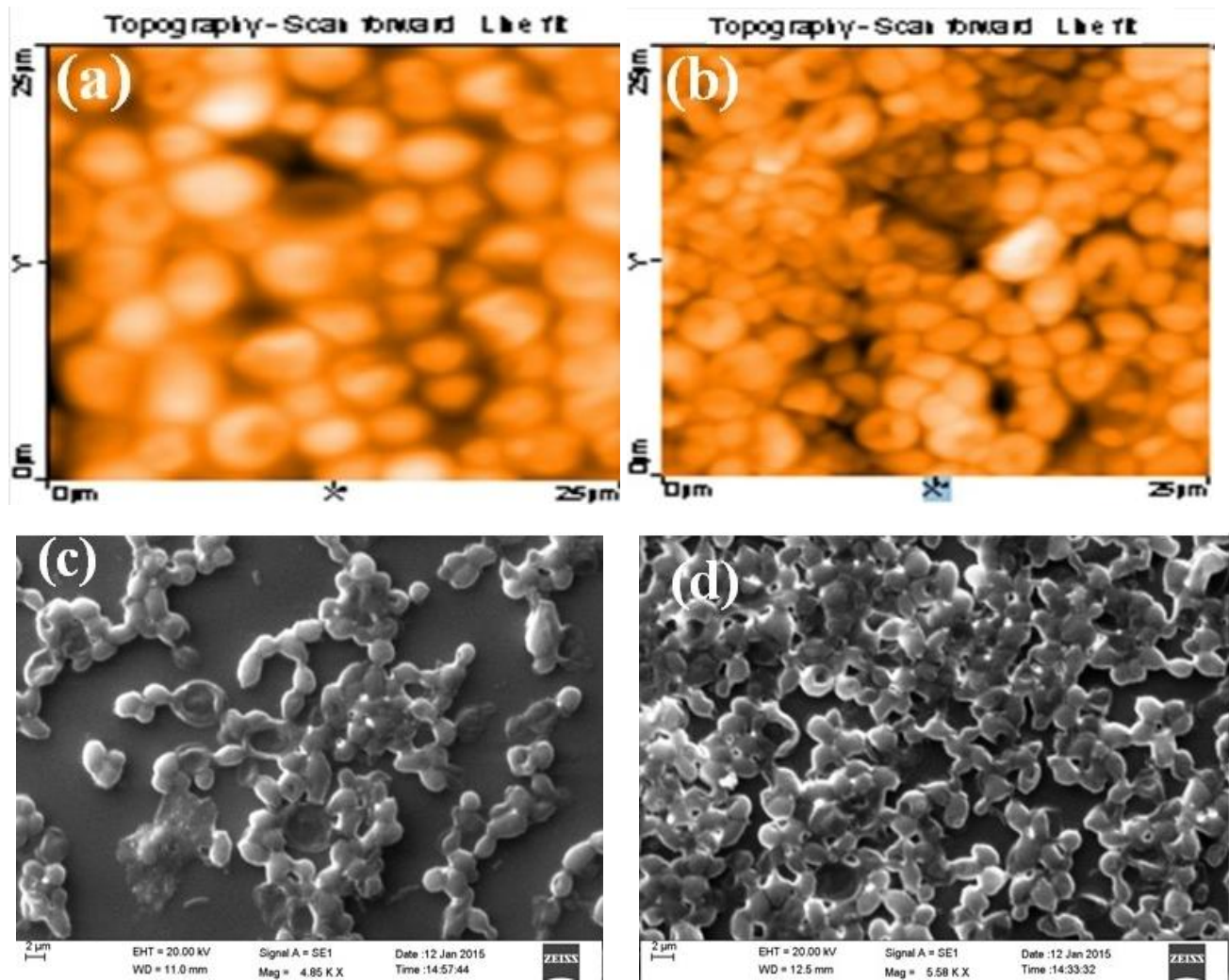

Fig. 2: AFM and SEM micrographs showing sequential biofilm formation by Candida sp. SMN04 at (a) $24 \mathrm{~h}$ and (b) $48 \mathrm{~h}$.
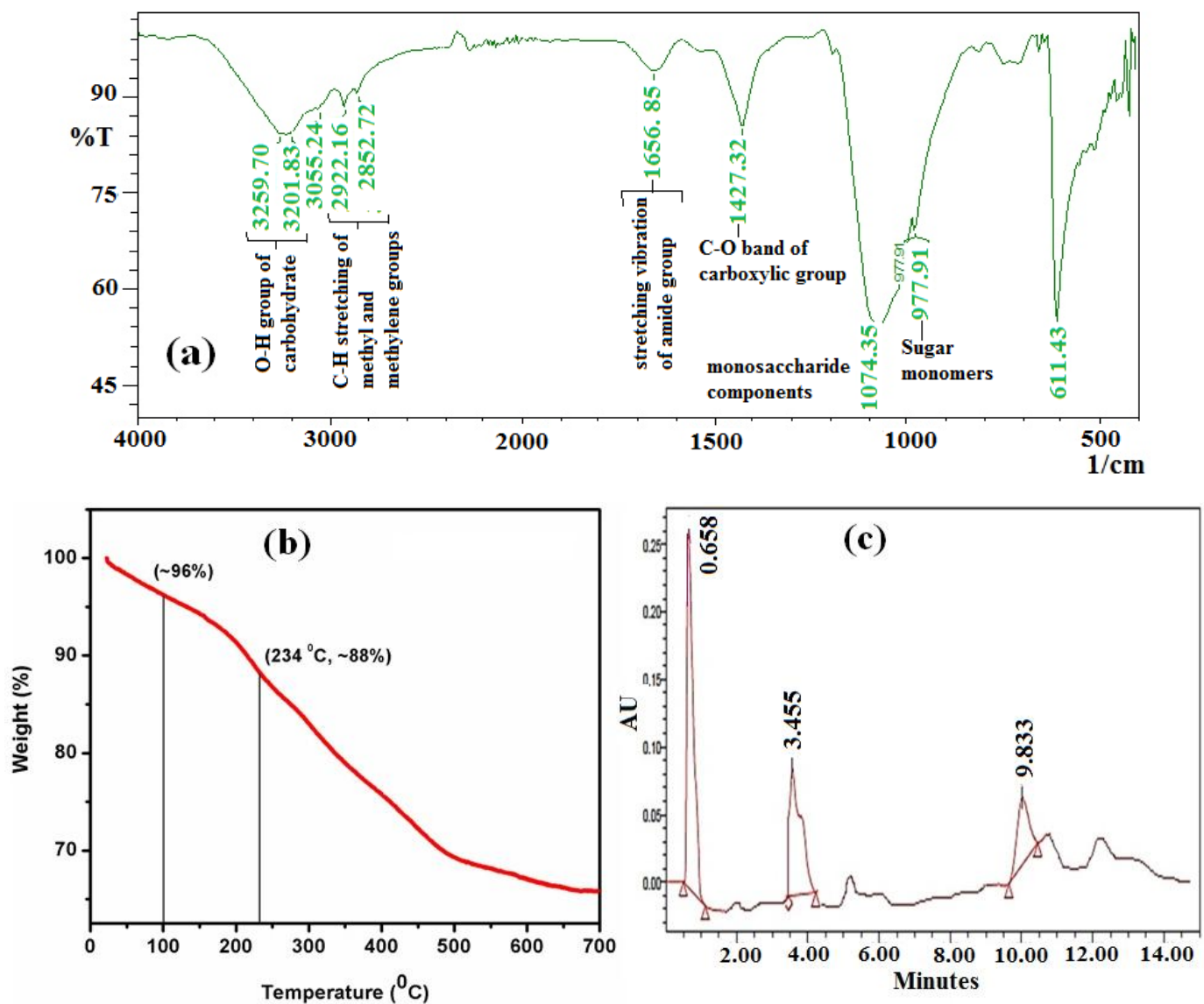

Fig. 3: Characterization of EPS produced by Candida sp. SMN04 EPS (a) FTIR spectrum (b) Thermogravimetric analysis (TGA), and (c) HPLC analysis of acid hydrolyzed exopolysaccharides (EPS). 


\section{Degradation of cefdinir present in pharmaceutical wastewater}

The pharmaceutical wastewater was analyzed for various physico-chemical parameters such as, color, $\mathrm{pH}, \mathrm{COD}, \mathrm{BOD}$, TDS, TSS etc following standard procedures. The initial concentration of cefdinir present in the effluent was found to be $175 \mathrm{mg} \mathrm{L}^{-1}$ (Selvi and Das, 2014a).

Experiments were conducted to confirm the suitability of PVA-alginate-immobilized yeast and biofilm formed on gravels towards removal of cefdinir from pharmaceutical wastewater. In batch mode, cefdinir degradation by PVA-alginate immobilized yeast cells and biofilm showed $96.6 \pm 0.8 \%$ and $92.2 \pm 0.5 \%$ over a period of $48 \mathrm{~h}$. Whereas in column mode, PVA-alginate immobilized yeast showed $93.5 \pm 1.1 \%$ and yeast biofilm showed $90.4 \pm 0.9 \%$ of cefinir degradation over a period of $48 \mathrm{~h}$ (Fig. 4). Packed bed column studies showed that the cefdinir degradation in the pharmaceutical effluent was faster in the initial stages and it proceeded in a slower pace as the time increased. The total reaction time was $48 \mathrm{~h}$, which was very much lower compared to batch studies. This may be due to the presence of cefdinir at low concentration $\left(175 \mathrm{mg} \mathrm{L}^{-1}\right)$ in pharmaceutical wastewater. Candida sp. SMN04 has already been reported to degrade $250 \mathrm{mg} \mathrm{L}^{-1}$ of cefdinirin aqueous medium (Selvi and Das, 2014b).

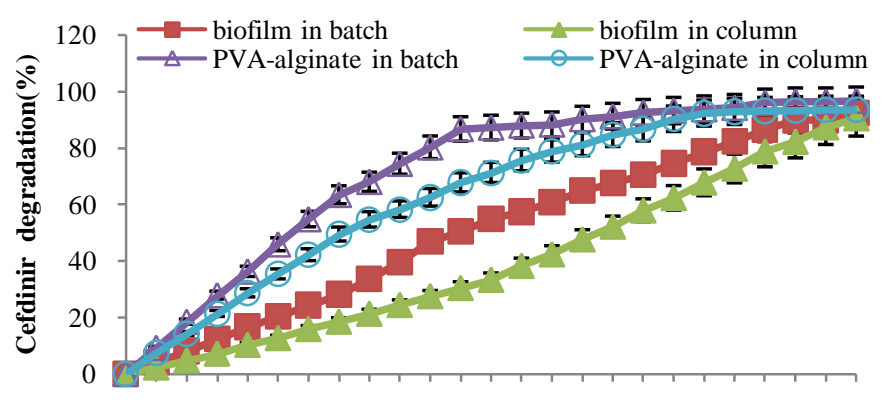

0244681012141618202224262830323436384042444648

Time (h)

Fig. 4: Degradation of cefdinir in pharmaceutical wastewater using yeast biofilm and PVA-alginate immobilized Candida sp. SMN04 in batch and column mode. The data presented are the mean of triplicates.

Thus, it can be inferred that, PVA-alginate immobilized yeast cells showed higher cefdinir degradation efficiency compared to yeast biofilm. This may be due to PVA, one of the most preferred matrix for cell immobilization in various waste water treatment because of the allowance of oxygen and substrate to diffuse inside the pores to make the biodegradation process more efficient (Cheng et al., 2012).

\section{CONCLUSIONS}

The results of the present study showed that PVAalginate immobilized yeast cells are more efficient compared to yeast biofilm towards degradation of cefdinirfrom aqueous environment. Therefore, application of immobilized yeast may serve as an effective remediation tool for the treatment of pharmaceutical wastewater containing cephalosporin antibiotics.

\section{ACKNOWLEDGEMENTS}

Authors would like to thank VIT university for providing laboratory facility and financial support for the smooth conduct of the work.

\section{REFERENCES}

Ahmed Z, Wang Y, Anjum N, Ahmad H, Ahmad A, Raza M. Characterization of new exopolysaccharides produced by coculturing of $L$. kefiranofaciens with yoghurt strains. Internat J Biolog Macromol., 2013; 59: $377-383$.

American Public Health Association (APHA). 2005. Standard methods for the examination of water and wastewater. 21st Ed Part 4000., Washington DC, USA.

Arriaga FM, Torres-Palma RA, Pétrier C, Esplugas S, Gimenez J, Pulgarin C. Mineralization enhancement of a recalcitrant pharmaceutical pollutant in water by advanced oxidation hybrid processes. Water Res., 2009; 43: 3984-3991.

Behera SK, Kim HW, Oh JE, Park HS. Occurrence and removal of antibiotics, hormones and several other pharmaceuticals in wastewater treatment plants of the largest industrial city of Korea. Sci Total Environ., 2011; 409: 4351-4360.

Benitez FJ, Acero JL, Real FJ, Roldan G, Casas F. Comparison of different chemical oxidation treatments for the removal of selected pharmaceuticals in water matrices. Chem Eng J., 2011; 168: 1149-1156.

Cabri W, Ghetti P, Alpegiani M, Pozzi G, Justo-Erbez A, PerezMartınez JI, Villalo'n-Rubio R, Monedero-Perales MC, Muñz-Ruiz A. Cefdinir: a comparative study of anhydrous vs. monohydrate form microstructure and tableting behaviour. Eur J Pharm Biopharm., 2006; 64: 212-221.

Chandran P and Das N. Degradation of diesel oil by immobilized Candida tropicalis and biofilm formed on gravels. Biodegradation., 2011; 22: 1181-1189.

Cheng Y, Lin H, Chen Z, Megharaj M, Naidu R. Biodegradation of crystal violet using Burkholderia vietnamiensis $\mathrm{C} 09 \mathrm{~V}$ immobilized on PVA-sodium alginate-kaolin gel beads. Ecotoxicol Environ Saf., 2012; 83: 108-114.

Duan H. Study on the treatment process of wastewater from cephalosporin production. J Sustain Dev., 2009; 2: 133 136.

El-Naas MH, Mourad AHI, Surkatti R. Evaluation of the characteristics of polyvinyl alcohol (PVA) as matrices for the immobilization of Pseudomonas putida. Internat J Biodeterior Biodegrad., 2013; 85: 413-420.

Endimiani A, Rossano A, Kunz D, Overesch G, Perreten V. First countrywide survey of third-generation cephalosporin-resistant Escherichia coli from broilers, swine, and cattle in Switzerland. Diagn Microbiol Infect Dis., 2012; 73: 31-38.

Godjevargova T, Mihova S, Gabrovska K. Fixed bed biosorption of $\mathrm{Cu} 2+$ by polyacrylonitrile-immobilized dead cells of Sacchromyces cerevisiae. World J Microbiol Biotechnol., 2004; 20: 273 279.

Homem V and Santos L. Degradation and removal methods of antibiotics from aqueous matrices. J Environ Manage., 2011; 92: 23042347.

Hawser SP and Douglas LS. Biofilm formation by Candida species on he surface of the catheter materials invitro. Infect Immun., 1994; 62: 287-295.

Idris A, Suzana W. Effect of sodium alginate concentration, bead diameter, initial $\mathrm{pH}$ and temperature on lactic acid production from pineapple wasteusing immobilized Lactobacillus delbrueckii. Process Biochem., 2006; 41:1117-1123.

Ismail B and Nampoothiri KM. Production, purification and structural characterization of an exopolysaccharide produced by a probiotic Lactobacillus plantarum MTCC 9510 Arch Microbiol., 2010; 192: 1049-1057. 
Kadakol JC, Kamanavalli CM, Shouche Y. Biodegradation of carbofuranphenol by free and immobilized cells of Klebsiella pneumonia ATCC13883T. World J Microbiol Biotechnol., 2011; 27: 25-29.

Karbowiak T, Ferret E, Debeaufort F, Voilley A, Cayot C. Investigation of water transfer across thin layer biopolymer films by infrared spectroscopy. J Membrane Sci., 2011; 370: 82-90.

Krishnan S, Roach B, Kasinathan K, Annamalai P, Nooruddin $\mathrm{T}$, Gunasekaran M. Studies on the biodegradation of cephalosporin drugs in pharmaceutical effluent using Pseudomonas putida and Pseudomonas fluorescence. Botany., 2012; July 7-11.

Kumar CG, Joo HS, Kavali R, Choi JW, Chang CS. Characterization of an extracellular biopolymer flocculant from a haloalkalophilic Bacillus isolate. World J Microbiol Biotechnol., 2004; 20: 837-843.

Lal P, Sharma D, Pruthi P, Pruthi V. Exopolysaccharide analysis of biofilm forming Candida albicans. J App Microbiol., 2010; 109: 128-136.

Laws A, Gu Y, Marshall V. Biosynthesis, characterisation, and design of bacterial exopolysaccharides from lactic acid bacteria. Biotechnol Adv., 2001; 19: 597-625.

Liu YJ, Zhang AN, Wang XC. Biodegradation of phenol by using free and immobilized cells of Acinetobacter sp. XA05 and Sphingomonas sp. FG03. Biochem Eng J., 2009; 44: 187-192.

Magrí A, Vanotti MB, Szögi AA. Anammox sludge immobilized in polyvinyl alcohol (PVA) cryogel carriers. Bioresour Technol., 2012; 114: 231-240.

O'Toole GA and Kotler R. Initiation of biofilm formation in Psuedomonas fluorescens WCS365 proceeds via multiple convergent signalling pathways: A genetic analysis. Mol Microbiol., 1998; 28: 449461.

Poli A, Anzelmo G, Tommonaro G, Pavlova K, Casaburi BN. Production and chemical characterization of an exopolysaccharide synthesized by psychrophilic yeast strain Sporobolomyces salmonicolor AL1 isolated from Livingston island Antarctica. Folia Microbiologica., 2010; 55: 576-581.

Sajna KV, Sukumaran RK, Gottumukkala LD, Jayamurthy H, Dhar KS, Pandey A. Studies on structural and physical characteristics of a novel exopolysaccharide from Pseudozyma sp. NII 08165. Internat J Biol Macromol., 2013; 59: 84- 89.

Sarma SJ and Pakshirajan K. Surfactant aided biodegradation of pyrene using immobilized cells of Mycobacterium frederiksbergense Internat Biodeterior Biodegrad., 2011; 65: 73-77.

Sasaki H, Nonaka J, Sasaki T, Nakai Y. Ammonia removal from livestock wastewater by ammonia-assimilating microorganisms immobilized in polyvinyl alcohol. J Ind Microbiol Biotechnol., 2006; 34: 105-110.

Selvi A, Salam JA, Das N. Biodegradation of cefdinir by a novel yeast strain, Ustilago sp. SMN03 isolated from pharmaceutical wastewater. World J Microbiol Biotechnol., 2014a; 30: 2839-2850.
Selvi A, Das N. Isolation, screening and identification of cefdinir degrading yeasts for the treatment of pharmaceutical wastewater. Int J Pharm Pharm Sci., 2014b; 6: 382-386.

Singh RP, Shukla MK, Mishra A, Kumari P, Reddy CRK, Jha B. Isolation and characterization of exopolysaccharides from seaweed associated bacteria Bacillus licheniformis. Carbohyd Polym., 2011; 84: $1019-1026$.

Stoodley P, Sauer K, Davies DG, Costerton JW. Biofilms as complex differentiated communities. Annu Rev Microbiol., 2002; 56: 187-209.

Tao F, Biao GZ, Yu JZ, Ning ZH. Isolation and characterization of an acidic polysaccharide from Mesona Blumes gum. Carbohyd Polym., 2008; 71: 159-169.

Tavares AMP, Agapito MSM, Coelho MAZ, Silva LJA, Barros Timmons A, Coutinho JAP, Xavier AMRB. Selection and optimization of culture medium for exopolysaccharide production by Coriolus (Trametes) Versicolor. World J Microbiol Biotechnol., 2005; 21: 1499-1507.

Tong K, Zhang Y, Liub G, Yeb Z, Chu PK. Treatment of heavy oil wastewater by a conventional activated sludge process coupled with an immobilized biological filter. Internat Biodeterior Biodegrad., 2013; 84: $65-71$.

Wagner RD, Johnson SJ, Cerniglia CE, Erickson BD. Bovine intestinal bacteria inactivate and degrade Ceftiofur and ceftriaxone with multiple $\beta$-lactamases. Antimicrobiol Agents Chemother., 2011; 55: 49904998.

Wang Y, Li C, Liu P, Ahmed Z, Xiao P, Bai X. Physical characterization of exopolysaccharide produced by Lactobacillus plantarum KF5 isolated from Tibet Kefir. Carbohyd Polym., 2010; 82: 895-903.

Wang Z, Xu Y, Wang H, Zhao J, Gao D, Li F, Xing B. Biodegradation of crude oil in contaminated soils by free and immobilized microorganisms. Pedosphere., 2012; 22: 717-725.

Whiteley CG and Lee DJ. Bacterial diguanylate cyclases: Structure, function and mechanism in exopolysaccharide biofilm development. Biotechnol Adv., 2015; 33: 124-141.

Yujian W, Xiaojuan Y, Hongyu L, Wei T. Immobilization of Acidithiobacillus ferrooxidans with complex of PVA and sodium alginate Poly Degrad Stabil., 2006; 91: 2408-2414.

Zhang LS, Wu WZ, Wang JL. Immobilization of activated sludge using improved polyvinyl alcohol (PVA) gel. J Environ Sci., 2007; 19: 1293-1297.

\section{How to cite this article:}

Adikesavan Selvi, Monidipa Banerjee, Nilanjana Das. Degradation of cefdinir from pharmaceutical wastewater using immobilized Candida sp. SMN04 and biofilm formed on gravels. J App Pharm Sci, 2015; 5 (10): 073-079. 